\title{
PREPARATION AND EVALUATION OF CARBOXYMETHYL ENSET AND CASSAVA STARCHES AS PHARMACEUTICAL GELLING AGENTS
}

\author{
Tesfaye Gabriel $^{1}$, Anteneh Belete ${ }^{1}$ and Tsige Gebre-Mariam1 ${ }^{*}$ \\ ${ }^{\mathbf{1}}$ Department of Pharmaceutics and Social Pharmacy, School of Pharmacy, College of Health Sciences, Addis Ababa \\ University, P. O. Box 1176, Addis Ababa, Ethiopia. \\ Email addresses: tesfu.gabriel@gmail.com, antbeletes@yahoo.com, respectively. \\ *Correspondence: Tsige Gebre-Mariam, \\ Phone: +251911242095, e-mail: tsigegmwm@gmail.com \\ Alternate Email: antbeletes@yahoo.com
}

\begin{abstract}
Starch is usually modified either chemically, physically or enzymatically to augment its convenience for industrial use. In the current study, starches from Enset and cassava plants were carboxymethylated, and factors which affect the carboxymethylation process and degree of substitution (DS) were studied. The application of the carboxymethyl starches as alternative pharmaceutical gelling agents for topical delivery of drugs was alsoinvestigated. Accordingly, nine different topical gel formulations of ibuprofen were prepared. All formulations were evaluated with respect to cosmetic qualities, $\mathrm{pH}$, drug content, viscosity, spreadability, extrudability, in vitro drug release, anti-inflammatory activity and stability. The results showed that carboxymethylation was significantly affected by the starch source, reaction medium,temperature andtime. All ibuprofen gel formulations showed homogeneous appearance, smooth texture and pleasant odor.The $\mathrm{pH}$ values of the formulations ranged from 6.80 to 7.22. Ibuprofen content rangedbetween 98.76 and $100.20 \%$ ensuring the uniformity of the drug content. The cumulative percent ibuprofen released over $12 \mathrm{~h}$ across cellulose membrane ranged from $43.8 \% \mathrm{~cm}^{-2}$ to $84.5 \% \mathrm{~cm}^{-2}$. Spreadability, extrudability, the cumulative drug release and diffusion coefficient of ibuprofen were influenced not only by the rheological properties of the formulations but also by the nature of the modified starches. Physicochemically stable ibuprofen gels wereobtained with potent anti-inflammatory activities.

Keywords: Ensetstarch, cassava starch, carboxymethylation, degree of substitution, ibuprofen gel, in vitro drug release, antiinflammatory activity, stability study
\end{abstract}

\section{INTRODUCTION}

Starch is one of the most abundant and renewable biopolymers, which is very promising raw material, available at low cost for preparing various functional polymers. It is usually modified either physically, enzymatically or chemically to augment its convenience for industrial use.Physical modification involves the treatment of starch by physical means such as shear force, blending and thermal treatment ${ }^{l}$. Enzymatic modification usually involves hydrolysis and transglycosylation by carbohydrate enzymes ${ }^{2}$ and chemical modification is used to introduce desirable properties to starch for specific applications based on reaction of the free hydroxyl groups of the anhydrous glucose units (AGU) with functional groups of chemicals, resulting in starch derivatives ${ }^{3}$.Chemical modification is generally achieved through derivatization such as etherification, esterification, cross-linking and dual modification of starch, oxidation, dextrinization, acid-thinning or hydrolysis ${ }^{l}$.

Carboxymethylation is a well-knownderivatization process for polysaccharides, resulting in polyelectrolytes ${ }^{4}$. Carboxymethyl starch (CMS) has unique properties due to the presence of negatively charged functional group $\left(\mathrm{CH}_{2} \mathrm{COO}-\right)$ and is officially listed in the United States Pharmacopoeia (USP) and the British Pharmacopoeia $(\mathrm{BP})^{5,6}$.Carboxymethylation involves a two-step reaction: the first step is the alkalization of starch and in the second step, etherification occurs ${ }^{7,8}$.
Enset(Enseteventricosum(Welw.)Cheeseman) and cassava (ManihotesculentaCrantz.) which belong to the family Musaceae and Euphorbiaceae, respectively are starch-rich staple foods widely used in the southern and south-western regions of Ethiopia ${ }^{9,10}$. The application of native starch as pharmaceutical gelling agent has been reported but discouraging mainly because of the need for a high concentration and heating to obtain viscous gel, the opacity of the formed gel, and its poor stability compared to other gelling agents ${ }^{11}$. Several reports indicate that carboxymethylation improves aqueous dispersibility and cold storage stability of starch pastes ${ }^{12,13}$.These improved properties suggest the potential application of CMS as a pharmaceutical gelling agent. Thus, the aim of the present work was to prepare and evaluatecarboxymethylEnsetand cassava starches as potential pharmaceutical gelling agents for topical applications.

\section{MATERIALS AND METHODS}

\section{Materials}

\section{Plant materials}

Boullawas purchased from the local Enset cultivating farmers in Durame, KambataTembaro Zone, South Nations Nationalities People Region (SNNPR), Ethiopia and cassava tubers were obtained from local cassava cultivating farmers in Sawula, GamoGofa Zone, SNNPR, Ethiopia. 


\section{Chemicals and solvents}

Monochloroacetic acid (MCA) (Hopkin\& Williams Ltd, England) was obtained from Ethiopian Conformity Assessment Enterprise (ECAE). Triethanolamine (Fischer Chem Alert Guide, USA), sodium metabisulphite and hydrochloric acid (Guangzhou Jinhaunda Chemical Reagent Co. Ltd, China), isopropyl alcohol and glacial acetic acid (Riedel-de Haèn, Germany), methanol (ScharlauChemie SA, European Union), potassium dihydrogen phosphate (Sörensen, Leuren, Denmark), disodium hydrogen phosphate (Fizmerk chemicals, India), sodium hydroxide pellets (UNI-CHEM ${ }^{\circledR}$ chemical reagent, China), ethanol (Joseph Mills (Denaturants) Ltd, Liverpool, England), sodium chloride (Oxford Laboratory, Mumbai, India), and formalin (BDH Chemicals Ltd, England) were all used as received.

\section{Active pharmaceutical ingredients and excipients}

Ibuprofen raw material powder and its working standard (Satwik Drugs Limited, India), sodium carboxymethylcellulose(FMC Corporation, USA) and propylene glycol (Research-lab fine Chem. Industries, India) were kindly supplied by Cadila Pharmaceuticals Sh. Co., Ethiopia. Indomethacin and carrageenan (Sigma Chemical Co., USA) were obtained from Department of Pharmaceutical Chemistry and Pharmacognosy, School of Pharmacy, Addis Ababa University and Drug Research Directorate, Ethiopian Health and Nutrition Research Institute (EHNRI), respectively. Methyl parabenand propyl paraben (BDH Chemicals Ltd, England) were donated from the Ethiopian Pharmaceuticals Manufacturing Sh. Co. (EPHARM Sh. Co). All the materials were used as received.

\section{Test animals}

Mice of either sex (30-45 g) used in anti-inflammatory study were obtained from the animal houses at the School of Pharmacy and Department of Biology, Addis Ababa University, respectively.

\section{Methods}

\section{Enset starch isolation}

Starch from boulla was isolated according to the method described byGebre-Mariam and Schmidt ${ }^{9}$.

\section{Cassava starch extraction}

Starch from cassava tubers was extracted using the method described elsewhere by Da etal ${ }^{14}$.

\section{Preparation of carboxymethylEnset and cassava starches}

Carboxymethylenset starch (CMES) and carboxymethyl cassava starch (CMCS) were prepared according to the procedure described by Jieet $\mathrm{al}^{15}$ with slight modification. Briefly, $764 \mathrm{ml}$ of organic solvent either isopropanol (ISPA) or methanol, was first mixed with water to a total volume of about $955 \mathrm{ml}$. Subsequently, $250 \mathrm{~g}$ Enset or cassava starch, which had already been dried in an oven (Kottermann ${ }^{\circledR} 2711$, Germany) at $50{ }^{\circ} \mathrm{C}$ for $24 \mathrm{~h}$, was added to a glass jacketed batch reactor with four necked stoppers fitted with a reflux condenser.The reaction medium was mixed in the glass reactor at room temperature. The reactor content was run at eight different reaction conditions (Table1). Then, $86.4 \mathrm{~g} \mathrm{NaOH}$ in the form of pellets was added to the reaction mixture. After 15 min, $51 \mathrm{~g}$ MCA powder was added to start the etherification reaction. A speed adjustable impeller (IkaWerke, guni, Hamburg, Germany) was used to stir the reaction medium. The stirrer speed was set at $250 \mathrm{rpm}$ at the beginning of all reaction conditions but was reduced gradually. At the end, the reaction was stopped by neutralization with glacial acetic acid. The liquid supernatant was decanted and the product was washed several times with $80 \%$ methanol and finally with analytical grade methanol. The modified starch was finally dried in an oven (Kottermann ${ }^{\circledR} 2711$, Germany) at $50{ }^{\circ} \mathrm{C}$ for $24 \mathrm{~h}$, milled and passed through sieve size of $224 \mu \mathrm{m}$.

Table 1: Reaction conditions used for carboxymethylation of Enset and cassava starches

\begin{tabular}{|c|c|c|c|c|}
\hline $\begin{array}{c}\text { Reaction } \\
\text { condition }\end{array}$ & Starch source & $\begin{array}{c}\text { Reaction media } \\
\mathbf{( 8 0 \%} \mathbf{v} / \mathbf{v})\end{array}$ & Reaction temp. $\left({ }^{\circ} \mathbf{C}\right)$ & $\begin{array}{c}\text { Reaction time } \\
(\mathbf{h})\end{array}$ \\
\hline E-M-70-1 & Enset & Methanol & 70 & 1 \\
\hline C-M-70-1 & Cassava & Methanol & 70 & 1 \\
\hline E-I-70-1 & Enset & ISPA & 70 & 1 \\
\hline C-I-70-1 & Cassava & ISPA & 70 & 1 \\
\hline E-I-70-0.5 & Enset & ISPA & 70 & 0.5 \\
\hline C-I-70-0.5 & Cassava & ISPA & 50 & 0.5 \\
\hline E-I-50-1 & Enset & ISPA & 50 & 1 \\
\hline C-I-50-1 & Cassava & ISPA & \\
\hline
\end{tabular}

N.B.All reactions were conducted at starch/liquor ratio of 1:3; NaOH/reagent molar ratio of 4.0; and reagent/AGU molar ratio of 0.35 .

\section{Determination of degree of substitution (DS)}

One gram CMS was converted to the H-form by treating with excess $0.1 \mathrm{~N}$ aqueous $80 \%$ methanolic $\mathrm{HCl}$ in a 100 $\mathrm{ml}$ beaker with occasional stirring for $1 \mathrm{~h}$. It was then filtered and washed several times with aqueous $80 \%$ methanol solution under suction in a sintered glass funnel $\left(\right.$ OAKTON $^{\circledR}$, WP-15-1, Japan),. The resulting sample was dried in an oven (Kottermann ${ }^{\circledR} 2711$, Germany) at $100{ }^{\circ} \mathrm{C}$ for $1 \mathrm{~h}$ and cooled in a desiccator. A portion of sample weighing $0.25 \mathrm{~g}$ was placed into a $250 \mathrm{ml}$ conical flask and to this $100 \mathrm{ml} \mathrm{DW}$ was added, followed by $10 \mathrm{ml}$ of $0.1 \mathrm{~N}$ $\mathrm{NaOHsolution.} \mathrm{The} \mathrm{mixture} \mathrm{was} \mathrm{heated} \mathrm{over} \mathrm{a} \mathrm{boiling}$ water bath $\left(\mathrm{GFL}^{\circledR}, \mathrm{D} 3006\right.$, Germany) for $20 \mathrm{~min}$ until a clear solution resulted. The hot solution was then titrated with a standard $0.1 \mathrm{~N} \mathrm{HCl}$ solution to a phenolphthalein end-point. Similarly processed native starch was used as a correction factor for the blank. Each sample analysis was 
carried out in triplicate and the mean values were taken. The \%Carboxyl and DS were calculated according to the method described byKhalil et $\mathrm{al}^{16}$ as shown in Eqn. 1and 2, respectively.

$$
\begin{gathered}
\begin{array}{c}
\% \text { Carboxyl }=\left[\left(V_{b}-V\right) / w t\right] \\
\text { Eqn. } 1
\end{array} \\
\text { DS }=162 \times \% \text { Carboxyl } /[4500-58 \times \% \text { Carboxyl }]
\end{gathered}
$$

Eqn. 2

where, $V_{b}(\mathrm{ml})$ is the volume of $\mathrm{HCl}$ used for the titration of the blank; $V(\mathrm{ml})$ is volume of $\mathrm{HCl}$ used for titration of the sample; $w t$-is weight in $\mathrm{g}$ of sample or native starch; and $\mathrm{M}_{\mathrm{NaOH}}$-is molarity of $\mathrm{NaOH}$.

\section{Preparation of polymer gels and drug formulations}

Polymer gels were prepared by a method described by Kittipongpatanaet $\mathrm{al}^{11}$ by mixing the polymer powder at specified concentrations with distilled water (DW), and then allowing it to fully swell overnight before use.The modified starches, i.e., CMES and CMCS were prepared at concentrations of 6,8 and $10 \%(\mathrm{w} / \mathrm{w})$ and 8,10 and $12 \%$ (w/w), respectively. Na-CMC was used at concentrations of 1,2 and $3 \%(\mathrm{w} / \mathrm{w})$ as commercial gelling agent. In addition, nine different medicated formulations (F1-F9) were prepared using the three polymers at the same concentrations as in the blank gels (Table 2). Briefly, the medicated gel formulations were prepared by weighing 2.5 $\mathrm{g}$ of ibuprofen on an analytical balance (Mettler Toledo, PR 203, Switzerland) and dissolving it in a co-solvent of ethanol and propylene glycol (PG) (solution A). The preservatives, methyl paraben (MP) and propyl paraben (PP), were also dissolved in solution $\mathrm{A}$. The respective polymers were allowed to swell fully overnight in half portion of the water. Solution A was added into the polymer gel under continuous stirring to yield a homogenous dispersion, which in turn was neutralized with triethanolamine (TEA) to obtain a colorless gel. The weight of the formulation was finally adjusted to final weight of $50 \mathrm{~g}$ by adding DW.

Table 2:Percentage composition (w/w) of the different ibuprofen gel formulations

\begin{tabular}{|c|c|c|c|c|c|c|c|c|c|c|}
\hline Formula & Ibuprofen & CMES & CMCS & Na- CMC & Ethanol & PG & TEA & MP & PP & DW(qs) \\
\hline F1 & 5 & 6 & - & - & 10 & 10 & 3 & 0.135 & 0.027 & 100 \\
\hline F2 & 5 & 8 & - & - & 10 & 10 & 3 & 0.135 & 0.027 & 100 \\
\hline F3 & 5 & 10 & - & - & 10 & 10 & 3 & 0.135 & 0.027 & 100 \\
\hline F4 & 5 & - & 8 & - & 10 & 10 & 3 & 0.135 & 0.027 & 100 \\
\hline F5 & 5 & - & 10 & - & 10 & 10 & 3 & 0.135 & 0.027 & 100 \\
\hline F6 & 5 & - & 12 & - & 10 & 10 & 3 & 0.135 & 0.027 & 100 \\
\hline F7 & 5 & - & - & 1 & 10 & 10 & 3 & 0.135 & 0.027 & 100 \\
\hline F8 & 5 & - & - & 2 & 10 & 10 & 3 & 0.135 & 0.027 & 100 \\
\hline F9 & 5 & - & - & 3 & 10 & 10 & 3 & 0.135 & 0.027 & 100 \\
\hline
\end{tabular}

\section{Physicochemical evaluation of the gels}

Visual appearance and cosmetic qualities. All prepared gels were physically inspected for clarity/transparency, color, odor, texture, consistency, and homogeneity after they have been filled intoglass jars. The prepared gels were also evaluated for the presence of particles or aggregates.

pH.The $\mathrm{pH}$ of each gel formulation was measured using a pH meter (model PH-210, HANNA instruments, Portugal) which has been pre-calibrated with standard buffer solutions of $\mathrm{pH} \mathrm{4,7}$ and 10. The samples were in contact with the $\mathrm{pH}$ electrode until the reading stabilized. The electrode was thoroughly rinsed with DW between each determination to remove all traces of the sample. The averages of three readings wererecorded as $\mathrm{pH}$ values.

Drug content determination.Specific quantity (100 mg) from each prepared gel was withdrawn at random from three different sampling points i.e., from the upper, middle and lower portionsof each batch and dissolved in $50 \mathrm{ml}$ of phosphate buffer saline (PBS, pH 7.4) and $2.5 \mathrm{ml}$ aliquot was diluted in $25 \mathrm{ml}$ volumetric flask. The volumetric flask containing the gel solution was vigorously mixed to ensure homogenous dispersion of the formulation ingredients. This solution was filtered and the concentration was estimated spectrophotometrically at 221 nm using $\mathrm{pH}$ 7.4 PBS as blank. The drug content was determined from standard calibration curve of ibuprofen in $\mathrm{pH}$ 7.4 PBS.

Rheological studies.The viscosities of the gel formulationsat different concentrations were determined at room temperature by a rotational viscometer (Kinematica, AG, Type ViscostarPlus L, Switzerland) using different spindle numbers L1, L2, L3, and L4 at different shear rates: $0.5,1,5,10,20,30,50,60,100$ and $200 \mathrm{rpm}$. The gels were placed in the sample holder and the suitable spindle selected was carefully lowered perpendicularly into the sample such that the spindle does not touch the bottom of the container. The spindle was attached to the viscometer and then it was allowed to rotate at a defined speed at room temperature to obtain stable viscosity reading.

Gel clarity. Gel clarity was determined by placing a sample of polymer gel or gel preparation in a disposable cuvette and measuring the absorbance at $700 \mathrm{~nm}$ using a 
spectrophotometer (CECIL, 1021, 1000 series, England) against water as blank ${ }^{11}$.

Spreadabilityof ibuprofen gel formulations.Concentric circles of different radii were drawn on graph paper and a $400 \mathrm{~cm}^{2}$ glass plate was fixed onto it. Gel $(1.0 \mathrm{~g})$ was transferred to the centre of the lower plate and spread over a diameter of $2.4 \mathrm{~cm}$. Another $400 \mathrm{~cm}^{2}$ glass plate of $185 \mathrm{~g}$ was placed gently on the gel and a standardized weight of $170 \mathrm{~g}$ was allowed to rest on the upper glass plate for 3 min. The increase in the diameter due to gel spreading was recorded $^{17}$.

Extrudability.The method adopted for evaluating gel formulation for extrudability was based on the quantity in percentage of gel extruded from tube on application of certain load. The formulation under study was filled in a clean, lacquered aluminum collapsible tube with a nozzletip of $5 \mathrm{~mm}$ opening. It was then placed between two glass slides and was clamped. Extrudability was determined by weighing the amount of gels extruded through the tip when a constant load of $1 \mathrm{Kg}$ was placed on the slides. The percentage of gel extruded was calculated and grades were allotted (++++ excellent, if $>90 \%$ of gel extruded; +++ very good, if $80-89.9 \%$; ++ good, if $70-79.9 \%$; + fair, if $50-69.9 \%$ and 0 poor, if $<50 \%$ of gel extruded $)^{18}$.

\section{In vitrodrug release study}

One gram gel sample of each formulation that corresponds to $50 \mathrm{mg}$ of ibuprofen was carefully weighed and placed on cellulose acetate membrane (Sartorius, Goettingen, Germany) with an average pore size of $0.45 \mu \mathrm{m}$ which was previously soaked in PBS ( $\mathrm{pH}$ 7.4) for $60 \mathrm{~min}$ and fixed to one end and made water-tight with aid of rubber band in an apparatus consisting of cylindrical tube with both ends open, $100 \mathrm{~mm}$ in height, $12.9 \mathrm{~mm}$ outer diameter and 12.1 $\mathrm{mm}$ inner diameter (release area $=115 \mathrm{~mm}^{2}$ ) as a diffusion cell. The tubes were submerged in a 1000-ml beaker containing $400 \mathrm{ml}$ PBS (pH 7.4) as receptor medium and equipped with stirring and temperature-controlling devices. The whole assembly was fixed insuch a way that the lower end of the cell containing the gel just touched (1-2 mm deep) the diffusion medium.The release test was carried out at a controlled stirring rate of $100 \mathrm{rpm}$ to ensure sink condition and a temperature of $37 \pm 1{ }^{\circ} \mathrm{C}$ by means of water jacket surrounding each cell. At 5, 15, 30, 60, 120, $180,240,300,360,480,600$ and $720 \mathrm{~min}, 5 \mathrm{ml}$ of the buffer containing the released ibuprofen was withdrawn from the beaker and replenished by the same volume of fresh buffer at $37 \pm 1{ }^{\circ} \mathrm{C}$ to maintain constant volume. The withdrawn sample was diluted to an appropriate volume and the absorbance was measured spectrophotometrically at $221 \mathrm{~nm}$ and the amount of ibuprofen released from the gel formulations was calculated based on the established standard calibration curve. Each sample was tested six times and mean values were taken ${ }^{19}$.

\section{Kinetics and mechanism of drug release}

To analyze the mechanism of drug release from the gel preparations, the release data were fitted to the following equations $^{20}$ :

\section{i. Zero - order equation: \\ @ 2011, JDDT. All Rights Reserved}

$$
Q=Q_{o}-K_{o} t \quad \text { Eqn. } 3
$$

where, $Q_{o}$ is the amount of drug present initially, $Q$ is the amount of drug remaining at time t, and $K_{o}$ is the zero order release rate.

\section{ii. First - order equation:}

$$
\ln Q=\ln Q_{o}-K_{1} t \quad \text { Eqn. } 4
$$

where, $Q_{o}$ is the amount of drug present initially, $Q$ is the amount of drug remaining at time $\mathrm{t}$, and $K_{1}$ is the first order release rate constant.

\section{iii. Higuchi's equation:}

$$
Q=2 C_{o} \sqrt{\left(\mathrm{D}_{a p p} \times \mathrm{t} / \pi\right)}
$$

where, $Q$ is the amount of drug released per unit area at time $\mathrm{t}\left(\mathrm{mg} \mathrm{cm}^{-2}\right), \mathrm{t}$ is the time after the application (sec), $C_{o}$ is the initial drug concentration in the donor chamber ( $\mathrm{mg}$ $\mathrm{cm}^{-3}$ ), $\pi$ is a constant and $\mathrm{D}_{a p p}$ is the apparent diffusion coefficient $\left(\mathrm{cm}^{2} \mathrm{sec}^{-1}\right) ; \mathrm{D}_{a p p}$ is calculated from the slope $K$ (apparent release rate) of the linear plot of $Q$ versus $\mathrm{t}^{1 / 2}$; hence,

$$
\mathrm{D}_{a p p}=K^{2} \pi / 4 C_{o}{ }^{2} \quad \text { Eqn. } 6
$$

\section{Anti-inflammatory activity study}

Anti-inflammatory activity of the medicated gel formulations was performed using carrageenan-induced paw edema method. The mice of either sex weighing 30$45 \mathrm{~g}$ were fasted overnight, but water was allowed ad libitum. The animals were divided into six groups of five animals each. Group 1-3 (control) received non-medicated polymer gels prepared from $8 \%(w / w)$ CMES, $10 \%(w / w)$ $\mathrm{CMCS}$, and $2 \%(\mathrm{w} / \mathrm{w}) \mathrm{Na}-\mathrm{CMC}$ by gently rubbing the gels on the plantar surface of the left hind paw;similarly, groups 4, 5 and 6 (test) received $0.25 \mathrm{~g}$ of the medicated ibuprofen gel formulations prepared from the corresponding concentrations of the polymers (F2, F5 and $\mathrm{F} 8$, respectively). After $1 \mathrm{~h}, 0.05 \mathrm{ml}$ of $1 \%$ (w/w) suspension of carrageenan was injected into the left plantar surface of the hind paw of all groups using a syringe with needle (Shandong Zibo Shacchuan Medical Instrument Co., Ltd., China). The hind paw volume was measured at different time intervals for $5 \mathrm{~h}$ after carrageenan treatment using a plethysmometer(UGO BASILE, 7140, Italy). The percent inhibition in hind paw edema volume was calculated using the formula shown in Eqn. 7 and compared with those recorded for the control group.

$$
\% \text { Edema Inhibition }=\left(1-V_{t} / V_{c}\right) \times 100 \quad \text { Eqn. } 7
$$

where, $V_{t}$-is mean edema volume of test, $V_{c}$-is mean edema volume of control ${ }^{21}$.

\section{Stability studies}

Stability studies on selected formulations were carried out at different conditions, i.e., real time stability conditions $\left(25^{\circ} \mathrm{C} / 60 \% \mathrm{RH}\right)$, at accelerated conditions $\left(40{ }^{\circ} \mathrm{C} / 75 \% \mathrm{RH}\right)$ in stability chamber (Binder ${ }^{\circledR}$, England) and in refrigerator (LG, South Korea) at $4{ }^{\circ}$ Cfor 3 months. The gel formulations were then observed for different evaluation ISSN: 2250-1177 
parameters such as change in the consistency, color, odor, $\mathrm{pH}$, drug contents and phase separation or syneresis and compared with the initial formulations stored at room temperature ${ }^{22}$.

\section{Statistical analysis}

All data reported in this study are averages of triplicate determinations except for the in vitro drug release study $(n=6)$ and anti-inflammatory activity study $(n=5)$. Wherever appropriate, the data were subjected to statistical analysis using Instat +, V. 3.33 (Statistical Services Centre, The University of Reading, UK) and Origin ${ }^{\circledR}$, version 7.0 SR0 (OriginLab Corporation, MA, USA) assisted by MS Excel 2007. In all cases, individual differences between in vitro drug release profile, viscosity of gels, antiinflammatory study data and all other relevant data were evaluated using a Tukey's test for one-way analysis of variance (ANOVA). $P$ value of less than 0.05 was considered to be evidence for a significant difference.

\section{Results and discussion}

\section{Factors affecting degree of substitution}

The DS is defined as the average number of substituents per AGU, the monomer unit of starch which indicates the amount of carboxymethyl group formed. Since each AGU contains three hydroxyl groups at carbon numbers 2,3 , and 6 , the DS lies between zero and three ${ }^{4,8}$.Under the same conditions of carboxymethylation, the DS values of the CMS obtained from Enset starch were higher than those of the CMS obtained from cassava starch at all reaction conditions investigated indicating that origin influences the DS (Table 3). Highest DS (0.926) was obtained for the Enset starch when the reactor content was run at $70{ }^{\circ} \mathrm{C}$ for $1 \mathrm{~h}$ using ISPA as reaction medium (E-I-70-1); on the other hand, the least DS (0.158) was obtained for cassava starch in methanol as reaction medium at the same reaction condition (C-M-70-1).

Table 3: Effects of starch source, solvent media, reaction temperature and time on DS

\begin{tabular}{|c|c|c|c|c|}
\hline Reaction condition & $\begin{array}{l}\text { Product behavior } 10 \mathrm{~min} \\
\text { before removal from the } \\
\text { reactor }\end{array}$ & $\begin{array}{c}\% \text { Carboxyl (mean } \\
\pm \mathrm{SD})\end{array}$ & $\begin{array}{c}\text { DS }{ }^{(\text {mean }} \\
\pm \mathrm{SD})\end{array}$ & $\begin{array}{c}\text { Properties of } 6 \% \text { CMS } \\
\text { in water }\end{array}$ \\
\hline E-M-70-1 & Slightly stirrable & $6.51 \pm 0.180$ & $0.255 \pm 0.008$ & $\begin{array}{l}\text { Slightly turbid and gel } \\
\text { particles }\end{array}$ \\
\hline C-M-70-1 & $\begin{array}{l}\text { Easily mixed and } \\
\text { stirred }\end{array}$ & $4.14 \pm 0.360$ & $0.158 \pm 0.015$ & Paste/dispersion \\
\hline E-I-70-1 & $\begin{array}{l}\text { Strong gummy product; } \\
\text { not mixed }\end{array}$ & $19.32 \pm 0.453$ & $0.926 \pm 0.029$ & Stiff gel \\
\hline C-I-70-1 & Gummy product; not stirrable & $16.90 \pm 1.803$ & $0.778 \pm 0.010$ & Flowable gel \\
\hline E-I-70-0.5 & $\begin{array}{l}\text { Product very firm; } \\
\text { slightly mixed }\end{array}$ & $11.03 \pm 0.231$ & $0.463 \pm 0.017$ & Thin flowable gel \\
\hline C-I-70-0.5 & $\begin{array}{c}\text { Product moderately firm; } \\
\text { slightly mixed }\end{array}$ & $9.74 \pm 0.172$ & $0.401 \pm 0.008$ & Thin flowable gel \\
\hline E-I-50-1 & $\begin{array}{l}\text { Product less firm; } \\
\text { not easily mixed }\end{array}$ & $6.86 \pm 0.197$ & $0.271 \pm 0.001$ & $\begin{array}{l}\text { Weak and easily } \\
\text { flowable gel }\end{array}$ \\
\hline C-I-50-1 & $\begin{array}{l}\text { Product less firm; } \\
\text { less mixed }\end{array}$ & $5.26 \pm 0.276$ & $0.203 \pm 0.021$ & $\begin{array}{l}\text { Weak and easily } \\
\text { flowable gel }\end{array}$ \\
\hline
\end{tabular}

It is well known that the structural and physicochemical characteristics of starches are related to their botanical sources. Starch characteristics such as amylose content, branch chain length distribution of amylopectin, phosphate monoester, phospholipids and lipid contents affect their functional properties. The granule shape and size also affect the functional properties of starches ${ }^{23}$. The reported amylose content of Enset starch is $29 \%^{9}$ and that of cassava starch is $16.1 \%^{10}$. Moreover, Enset starch has been shown to have normal granule size distribution with a mean particle size of $46 \mu \mathrm{m}$ with characteristic morphology of somewhat angular and elliptical ${ }^{9}$ while that of cassava starch is $12.71 \mu \mathrm{m}$ showing spherical morphology ${ }^{10}$.The large size differences between Enset and cassava starches indicate that the surface area of the latter starch granules is larger rendering more $\mathrm{OH}$ groups at the surface which may lead to higher DS. However, on the contrary, Enset starch has significantly larger proportion of amylose that contributes to higher rate and extent of reaction and hence DS.
The choice of organic solvent also had a significant influence on DS (Table 3). This could be due to the high ability of ISPA to dissolve the etherifying agent and enhance starch swelling and viscosity when compared to methanol. Moreover, an increase in temperature enhances solubility of the etherifying agent and facilitates both the swelling of the starch molecules and the diffusion of the reactants. The CMS which were prepared using ISPA formed gel and then gummy mass, making stirring difficult; and it was also difficult to remove the products. These observations are consistent with the report of Lawalet $\mathrm{al}^{4}$ on carboxymethylcocoyam starch at higher temperatures. So, depending upon the DS and rheological properties, modified Enset and cassava starches obtained using reaction conditions E-I-70-1 and C-I-70-1were employed as gelling agents in subsequent investigations and designated as CMES and CMCS, respectively. 


\section{Physicochemical evaluation of gel formulations}

Nine different gel formulations of ibuprofen were prepared using CMES, CMCS and Na-CMC as gelling agents. The physicochemical properties of the gel formulations are shown in Table 4. All the prepared gel formulations shared good and smooth homogeneous appearance, and pleasant smell which was attributed to the presence of alcohol in the formulations. The ibuprofen gel formulations spread smoothly on a clean even glass plate with minimum pressure without any solid or gritty particles. Furthermore, the physical appearance of the gel formulations F7, F8 and F9 were transparent while formulations of the modified starches (F1-F6) were translucent.

The $\mathrm{pH}$ values of the gel formulations ranged from $6.80 \pm 0.02-7.22 \pm 0.06 \quad(n=3)$, within physiologically acceptable $\mathrm{pH}$ and, in principle, were devoid of any skin irritation $^{20,24,25}$.The uniform distribution of drug was confirmed by content uniformity studies. As depicted in Table 4, the ibuprofencontent in all gel formulations was found to range from $98.76 \pm 0.21-100.2 \pm 0.42 \%(n=3)$ of the theoretical value of $5 \%$, w/w which is within the acceptable limits $(95.0 \text { to } 105.0 \%)^{6}$ and ensured the uniformity of the drug content in the formulations.
Based on visual observation and absorbance measurementat $700 \mathrm{~nm}$, the clarity of the medicated CMS preparations was found to be much better than those of the corresponding polymer gels as depicted in Table 4. This could be due to the incorporation of TEA in the medicated gel formulations. TEA was incorporated to adjust the $\mathrm{pH}$ and to increase the solubility of the drug in the gel formulations ${ }^{26,27}$. However, it appears that TEA also has additional solubilizing effect on the polymer gel matrix. Formulations without TEA produced gels that were whitish cream with simultaneous precipitation of the drug as fine grit dispersions indicating the presence of chemical incompatibility due to $\mathrm{pH}$ variation. Further, it was observed that the absorbance readings of the gel formulations increased significantly with increasing concentration of the polymers showing that gel clarity was influenced by concentration and nature of polymer with the rank order of $\mathrm{Na}-\mathrm{CMC}>\mathrm{CMES}>\mathrm{CMCS}$.

The vehicle also plays a key role in the appearance, feel, and successful application of the topical preparations ${ }^{28}$. Clear or translucent homogenous gels are often preferred by consumers. Increasing the ethanol content in all formulations precipitated the CMS and $\mathrm{Na}$ CMC that led to the formation of two distinct phases, i.e., a clear solution and semi-solid layer.

Table 4: Physicochemical properties of the different ibuprofen gel formulations

\begin{tabular}{|c|c|c|c|c|c|c|c|}
\hline \multirow[t]{2}{*}{ Formula } & \multirow{2}{*}{$\begin{array}{c}\text { Physical } \\
\text { appearance }\end{array}$} & \multirow{2}{*}{$\begin{array}{c}\text { Ibuprofen } \\
\text { Content }(\%)\end{array}$} & \multirow[t]{2}{*}{$\mathrm{pH}$} & \multirow{2}{*}{$\begin{array}{l}\text { Extrud- } \\
\text { ability }\end{array}$} & \multirow{2}{*}{$\begin{array}{l}\text { Spreading } \\
\text { diameter } \\
(\mathrm{mm})\end{array}$} & \multicolumn{2}{|c|}{ Absorbance at $700 \mathrm{~nm}$} \\
\hline & & & & & & \multicolumn{2}{|c|}{ Polymer gelFormulation } \\
\hline F1 & Translucent & $100.2 \pm 0.42$ & $7.17 \pm 0.09$ & +++ & $88.16 \pm 1.73$ & $0.323 \pm 0.009$ & $0.203 \pm 0.016$ \\
\hline $\mathrm{F} 2$ & Translucent & $98.96 \pm 0.12$ & $7.21 \pm 0.01$ & ++ & $71.43 \pm 1.73$ & $0.386 \pm 0.004$ & $0.227 \pm 0.006$ \\
\hline F3 & Translucent & $99.32 \pm 0.64$ & $7.22 \pm 0.06$ & + & $53.98 \pm 1.16$ & $0.408 \pm 0.003$ & $0.301 \pm 0.015$ \\
\hline F4 & Translucent & $99.95 \pm 0.53$ & $6.86 \pm 0.02$ & ++ & $79.51 \pm 0.58$ & $0.456 \pm 0.029$ & $0.346 \pm 0.009$ \\
\hline F5 & Translucent & $99.81 \pm 0.21$ & $6.80 \pm 0.02$ & + & $69.32 \pm 1.16$ & $0.591 \pm 0.019$ & $0.421 \pm 0.019$ \\
\hline F6 & Translucent & $98.89 \pm 0.49$ & $6.83 \pm 0.03$ & + & $56.40 \pm 0.58$ & $0.718 \pm 0.004$ & $0.568 \pm 0.014$ \\
\hline F7 & Transparent & $99.95 \pm 0.74$ & $7.01 \pm 0.02$ & +++ & $87.05 \pm 1.16$ & $0.018 \pm 0.002$ & $0.017 \pm 0.000$ \\
\hline F8 & Transparent & $99.60 \pm 0.21$ & $6.98 \pm 0.09$ & ++ & $70.23 \pm 1.73$ & $0.022 \pm 0.001$ & $0.021 \pm 0.000$ \\
\hline F9 & Transparent & $98.76 \pm 0.21$ & $7.19 \pm 0.09$ & + & $55.74 \pm 2.31$ & $0.025 \pm 0.001$ & $0.024 \pm 0.000$ \\
\hline
\end{tabular}

The increase in diameter of ibuprofen gel formulations following the spreadability test was found to range from $53.98 \pm 1.16-88.16 \pm 1.73 \mathrm{~mm}(n=3)$. As the concentration of the polymer increased, the spreadability of the formulation decreased. As depicted in Table 4, F1, F4 and F7 showed the highest spreadability among the respective polymers: CMES, CMCS and Na-CMC depending upon the concentration of the polymers. Spreading of topically applied products affect drug delivery as reflected by dermatopharmacokineticstudies ${ }^{26}$. Formulations with higher spreadability values allow ease of application and thereby increased surface area available for drug permeation. A good gel takes less time to spread and will have high spreadability ${ }^{29,30}$.

Viscosity is an important physical parameter for characterizing gels as it affects the extrudability, spreadability, release of drug and other physicochemical properties $^{21}$.As shown in Fig. 1, the gel formulations showed decreasing viscosity with increased shear rate from 0.5 to $200 \mathrm{rpm}$ exhibiting a shear-thinning behavior. Moreover, ibuprofen gels prepared from CMES had significantly higher viscosity values than those of CMCS, both set of formulations exhibiting increased viscosity with increasing polymer concentration.

The apparent viscosity values of the CMS gels were found to be significantly higher when compared with the corresponding concentrations of the medicated formulations as depicted in Fig. 2.These results might be attributed to the relatively higher concentrations of ethanol and propylene glycol present in the medicated gel formulations that decrease the relative solubility and swellability of the polymers compared to the pure polymer gels $^{31}$. 


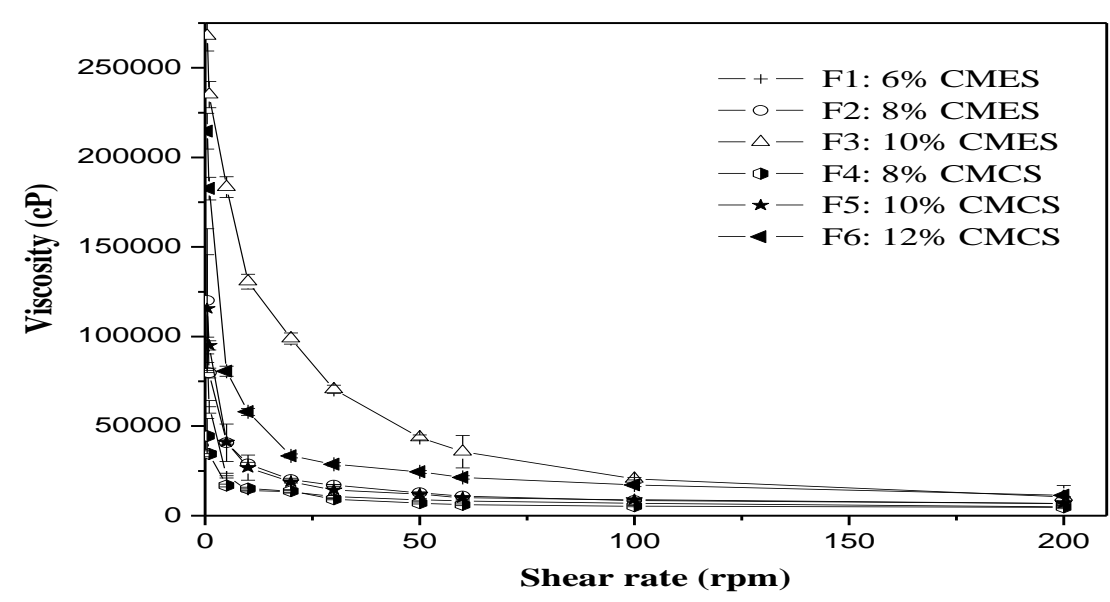

Figure 1: Plot of viscosity vs. shear rate for F1-F6 medicated gel formulations
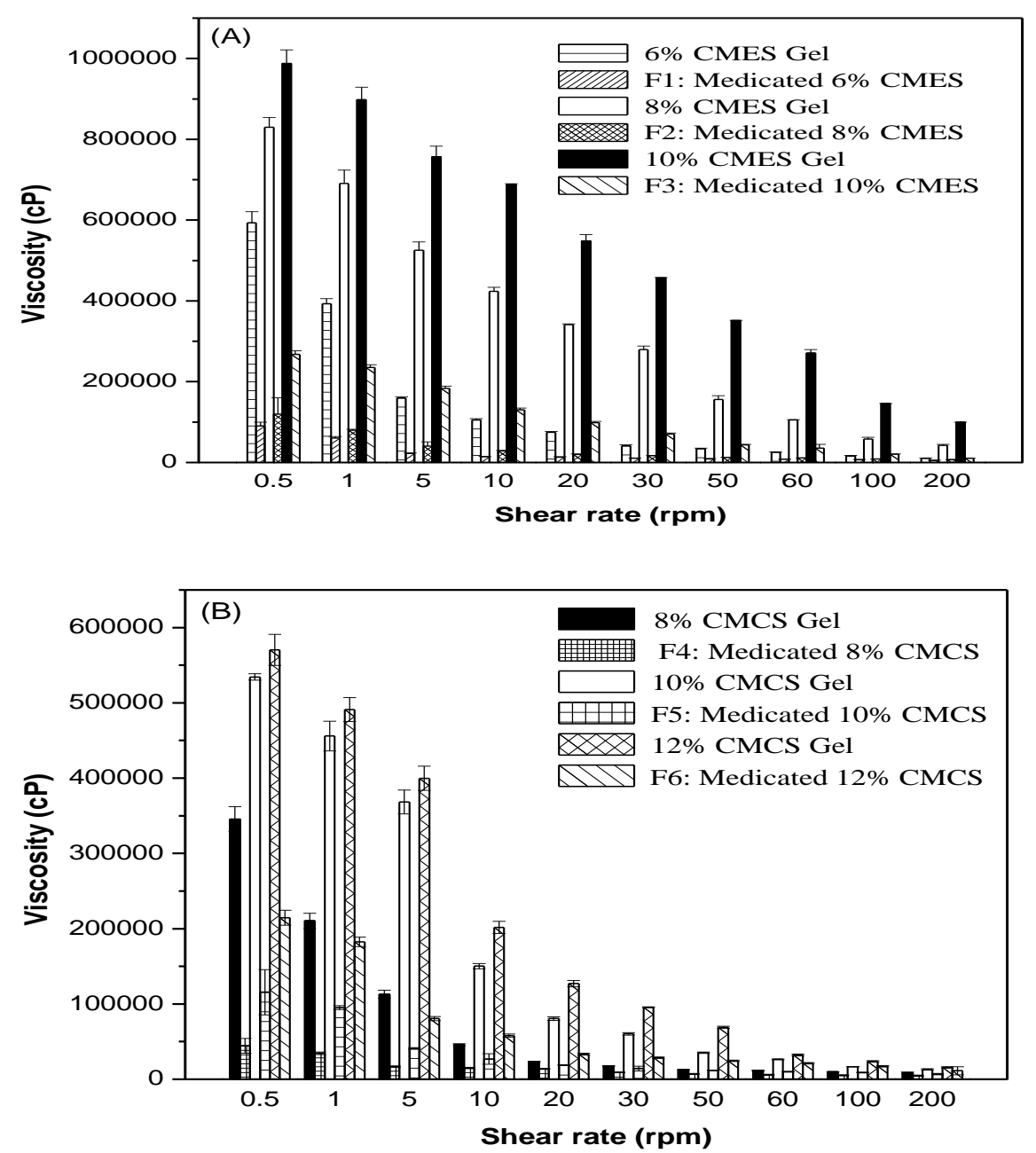

Figure 2: Viscosities of (A) CMES gels and corresponding medicated gel formulations (F1, F2 and F3), and (B) CMCS gels and corresponding medicated gel formulations (F4, F5 and F6) at different shear rates at room temperature.

\section{In vitrodrug release from gel formulations}

Fig. 3 shows the release profile of ibuprofen from the nine gel formulations using synthetic cellulose acetate as diffusion membrane. The results show that as the concentration of CMES, CMCS and Na-CMC in the gel formulations increased from $6-10 \%(\mathrm{w} / \mathrm{w}), 8-12 \%(\mathrm{w} / \mathrm{w})$ and $1-3 \%(w / w)$, the percent of ibuprofen released into the buffer medium gradually decreased from 84.5 to $43.8 \% / \mathrm{cm}^{2}, 77.6$ to $50.6 \% / \mathrm{cm}^{2}$ and 69.1 to $52.4 \% / \mathrm{cm}^{2}$, respectively. This decrease in the release is likely attributed to increased micro-viscosity, i.e., the environment through which the solute molecules travel as the polymer concentrations increase $\mathrm{s}^{32,33}$.

Ricci et al.(2005) reported that drug release from gels is controlled by gel dissolution and drug diffusion from the gel matrix ${ }^{34}$. In the diffusion process, there are believed be two steps: one is diffusion through the gel, and the other is diffusion through the membrane.The diffusion 
measurements obtained are thus a combination of both these processes ${ }^{35}$. It is possible that at higher polymer concentrations, the active substance will be trapped in smaller polymer cells as it will be structured by its close proximity to the polymer molecules and this increases the diffusional resistance. Rheological properties are known to be related to the gel structure, inter-chain interactions, and polymer chain entanglements, which in turn affect drug release and diffusion processes ${ }^{36,37}$. Further, when the drug diffusion through the vehicle is a rate limiting step, the viscosity of vehicles may play an important role in controlling the drug release ${ }^{38}$.
From the release profiles depicted in Fig. 3, it is observed that, initially $(\sim 1 \mathrm{~h})$, drug was released rapidly (burst effect) followed by a slow release for the rest of the release study period. The initial burst effect could be due to the release of the drug to the surface of the immediate barrier membrane. Thus, the molecule that is easily accessible to the solvent at the interface immediately diffuses into the receiver compartment establishing a burst effect. As the time advances, there exist greater resistance to the penetration of the solvent to the inside of the gel matrix resulting in a slower release rate thereby exhibiting retarded and steady release profile.

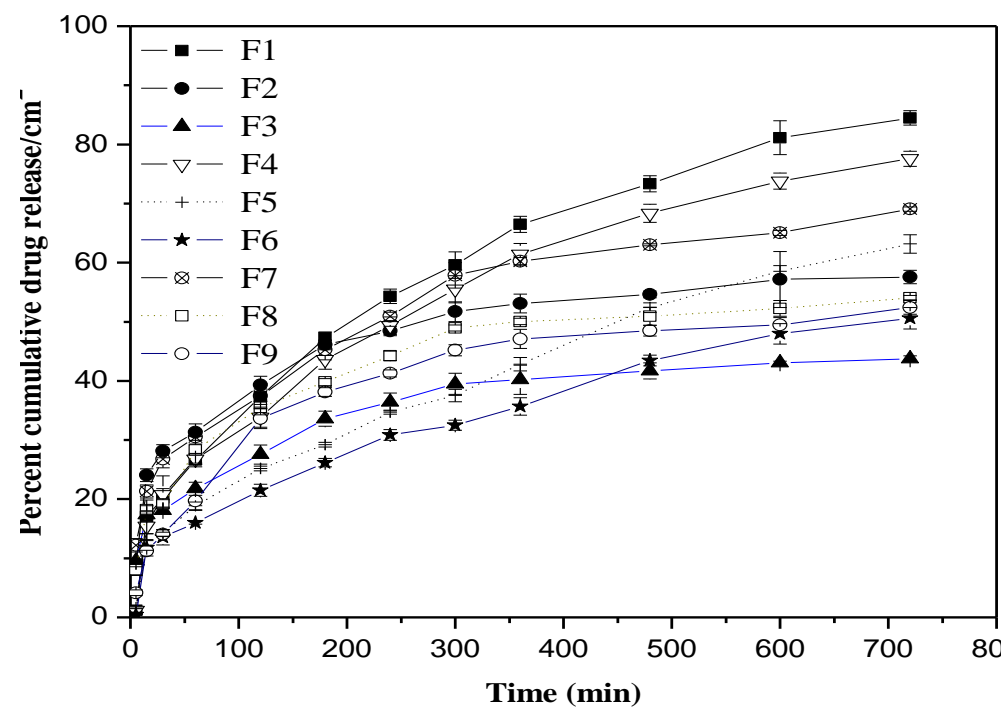

Figure 3: Release profiles of ibuprofen from gel formulations through synthetic cellulose acetate membrane.

\section{Drug release kinetics}

The drug release data were fitted to zero order, first order and Higuchi kinetic models and analysed. The results show that the Higuchi kinetic model best fitted the $12 \mathrm{~h}$ release profile as confirmed by the highestcorrelation coefficients shown in Table 5. This finding indicates that the ratecontrolling mechanism in the drug release process is the diffusion of the dissolved drug through the vehicle network to the external medium, which is in agreement with other studies ${ }^{20,28,39}$.

In addition, the drug diffusion coefficient $(D)$ was found to be affected by polymer content and nature of the polymer used.The diffusion coefficient values calculated from the
Higuchi plots for the different formulations were found to decrease inversely as a function of polymer concentration. The apparent release rate of ibuprofen from F1 (12.7 \pm $0.037 \mathrm{mg} \mathrm{cm}^{-2} \mathrm{~h}^{-1 / 2}$ ) is the largest of all the formulations and about 2.4 times higher than F3 which has the smallest release rate $\left(5.4 \pm 0.018 \mathrm{mg} \mathrm{cm}^{-2} \mathrm{~h}^{-1 / 2}\right)(\mathrm{p}<0.05)$. Drug release rate constant of $\mathrm{F} 4\left(11.6 \pm 0.015 \mathrm{mg} \mathrm{cm}^{-2} \mathrm{~h}^{-1 / 2}\right)$ is significantly higher when compared to F5 $(9.1 \pm 0.025 \mathrm{mg}$ $\left.\mathrm{cm}^{-2} \mathrm{~h}^{-1 / 2}\right)$ and F6 $\left(7.3 \pm 0.021 \mathrm{mg} \mathrm{cm}^{-2} \mathrm{~h}^{-1 / 2}\right)(\mathrm{p}<0.05)$. These findings support the fact that the release rate is influenced by the rheological properties of the formulations as well as the nature of the polymer composing the vehicle.

Table 5: Kinetic model fitting of thein vitro ibuprofen release profiles of the gel formulations.

\begin{tabular}{lccccc}
\hline Formula & \multicolumn{3}{c}{$\mathrm{R}^{2}$} & & $\mathrm{~K}\left(\mathrm{mg} \mathrm{cm}^{-2} \mathrm{~h}^{-1 / 2}\right)(\mathrm{mean} \pm$ \\
$\mathrm{SD})$ & & $\begin{array}{c}\left(\mathrm{D}, \mathrm{cm}^{2} \mathrm{sec}^{-1}\right) \times 10^{-5} \\
(\mathrm{mean} \pm \mathrm{SD})\end{array}$ \\
\cline { 2 - 4 } & Zero-order & First-order & Higuchi & & \\
\hline F1 & 0.894 & 0.935 & 0.986 & $12.7 \pm 0.037$ & $1.48 \pm 0.012$ \\
F2 & 0.722 & 0.753 & 0.893 & $6.9 \pm 0.047$ & $0.44 \pm 0.019$ \\
F3 & 0.772 & 0.788 & 0.931 & $5.4 \pm 0.018$ & $0.25 \pm 0.003$ \\
F4 & 0.889 & 0.926 & 0.984 & $11.6 \pm 0.015$ & $1.23 \pm 0.002$ \\
F5 & 0.945 & 0.966 & 0.985 & $9.1 \pm 0.025$ & $0.75 \pm 0.005$ \\
F6 & 0.919 & 0.940 & 0.982 & $7.3 \pm 0.021$ & $0.46 \pm 0.004$ \\
F7 & 0.844 & 0.872 & 0.967 & $8.8 \pm 0.031$ & $0.72 \pm 0.009$ \\
F8 & 0.747 & 0.771 & 0.916 & $7.7 \pm 0.014$ & $0.54 \pm 0.002$ \\
F9 & 0.758 & 0.782 & 0.921 & $7.1 \pm 0.017$ & $0.43 \pm 0.003$ \\
\hline
\end{tabular}


Formulations F2, F5 and F8 were selected from the ninemedicated gel formulations for furtherantiinflammatory activity as well as stability studies on the basis of physicochemical parameters evaluation and their representativeness.

\section{Anti-inflammatory activity:}

In control groups which received carrageenan alone, rapid andcontinuous increase in paw volume (i.e., inflammation) was observed andthe inflammation was sustained during the entire period of study.The test products (F2, F5 and F8) exhibited anti-inflammatory activity up to $5 \mathrm{~h}$ (Fig. 4). The highest anti-inflammatory activity was obtained in F5 (78 $\pm 0.392 \%)$, followed by F8 (68 $\pm 0.459 \%)$, and then F2 (59 $\pm 0.415 \%)$ after the $5^{\text {th }} \mathrm{h}$ study. The variation of activities could partly be attributed to the variation in the rate and extent of drug release as discussed in the in vitro release study.As shown in Table 5, F5 had the highest drug release rate and diffusion coefficient which contributed to itshighest anti-inflammatory effect.

\section{Stability studies}

None of the selected ibuprofen gel formulations (F2, F5 and F8) showed any appreciable change in gel clarity, physical appearance and homogeneity indicating physical stability when inspected at intervals of 1,2 , and 3 months as depicted in Table 6. Furthermore, no obnoxious odor was perceptible from any of the gel formulations. Even after exposure to heat and humidity, no significant change was observed in $\mathrm{pH}$ and drug content of the gel formulations. Besides, there was no appearance of air bubbles and crystals or precipitates during the stability study. Thus, all gel formulations were found to be stable under all storage conditions.

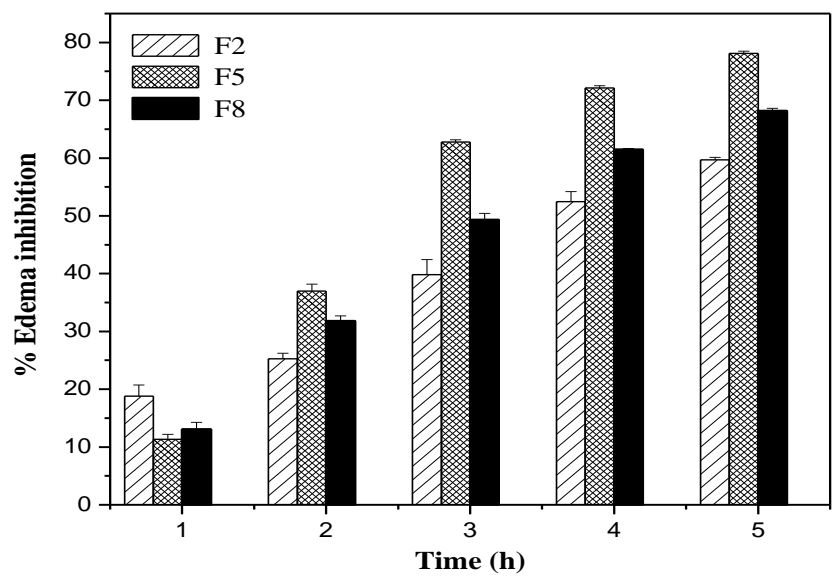

Figure4.Percent inhibitions of hind paw edemafollowing the application of ibuprofen gel formulations.

Table 6: Physicochemicalproperties of ibuprofen gel formulations after 3 months storage under different conditions

\begin{tabular}{llccllc}
\hline Formula & \multicolumn{1}{c}{$\begin{array}{c}\text { Storage } \\
\text { conditions }\end{array}$} & $\begin{array}{c}\text { Color change, } \\
\text { precipitate } \\
\text { formation }\end{array}$ & $\begin{array}{c}\text { Ibuprofen } \\
\text { content }(\%)\end{array}$ & $\begin{array}{l}\text { Physical } \\
\text { appearance }\end{array}$ & $\begin{array}{l}\text { Homog- } \\
\text { eneity }\end{array}$ & $\mathrm{pH}$ \\
\hline \multirow{2}{*}{$\mathrm{F} 2$} & $25^{\circ} \mathrm{C} / 60 \% \mathrm{RH}$ & $\mathrm{Nil}$ & $99.62 \pm 0.53$ & Translucent & Good & $7.17 \pm 0.02$ \\
& $40^{\circ} \mathrm{C} / 75 \% \mathrm{RH}$ & $\mathrm{Nil}$ & $98.72 \pm 0.34$ & Translucent & Good & $7.28 \pm 0.01$ \\
& $4{ }^{\circ} \mathrm{C}$ & $\mathrm{Nil}$ & $98.53 \pm 0.67$ & Translucent & Good & $7.24 \pm 0.06$ \\
F5 & $25^{\circ} \mathrm{C} / 60 \% \mathrm{RH}$ & $\mathrm{Nil}$ & $99.85 \pm 0.37$ & Translucent & Good & $6.96 \pm 0.04$ \\
& $40^{\circ} \mathrm{C} / 75 \% \mathrm{RH}$ & $\mathrm{Nil}$ & $99.31 \pm 0.51$ & Translucent & Good & $6.88 \pm 0.03$ \\
& $4{ }^{\circ} \mathrm{C}$ & $\mathrm{Nil}$ & $99.11 \pm 0.47$ & Translucent & Good & $6.86 \pm 0.02$ \\
$\mathrm{~F} 8$ & $25^{\circ} \mathrm{C} / 60 \% \mathrm{RH}$ & $\mathrm{Nil}$ & $99.71 \pm 0.52$ & Transparent & Good & $7.07 \pm 0.05$ \\
& $40^{\circ} \mathrm{C} / 75 \% \mathrm{RH}$ & $\mathrm{Nil}$ & $99.46 \pm 0.37$ & Transparent & Good & $7.15 \pm 0.09$ \\
& $4{ }^{\circ} \mathrm{C}$ & $\mathrm{Nil}$ & $98.58 \pm 0.31$ & Transparent & Good & $7.11 \pm 0.08$ \\
\hline
\end{tabular}

\section{CONCLUSIONS}

Carboxymethyl starches of Enset and cassava were prepared as a product of the reaction of starch and monochloroacetic acid in the presence of sodium hydroxide at different reaction conditions. Subsequently, nine topical gel formulations of ibuprofen were prepared based on the concentration and type of polymers as gelling agents using carboxymethylEnset starch (CMES), carboxymethyl cassava starch (CMCS) and sodium carboxymethylcellulose (Na-CMC).The results showed that carboxymethylation was significantly affected by the source of starch, reaction medium, reaction temperature as well as reaction time. Isopropyl alcohol offered a better medium for carboxymethylation compared to methanol. The drug release data of all gel formulations best fitted to Higuchi model when compared to zero order and first order kinetics following in vitro drug release studies over
$12 \mathrm{~h}$. The in vitro drug release results indicated that the cumulative drug release, the apparent release rate, and the diffusion coefficient of ibuprofen were influenced not only by the rheological properties of the formulations but also by the nature of the polymers. The anti-inflammatory activities of the medicated gel formulations in mouse hind paw edema model revealed that ibuprofen was delivered to the inflammation site at adequate level to significantly lower inflammation induced by carrageenan injection. The medicated gels also showedexcellent stability profile for at least 3 months under different storage conditions.

\section{ACKNOWLEDGEMENTS}

The study was sponsored by the School of Graduate Studies of the Addis Ababa University (AAU) and the Ethiopian Pharmaceutical Manufacturing Sh. Co. (EPHARM) is acknowledged for providing access to stability chamber. 


\section{REFERENCES}

1. Bemiller JN, Starch Modification: Challenges and Prospects, Starch/Stärke, 1997, 49, 127-131.

2. Lee C-K, Le Q-T, Kim Y-H, Shim J-H, Lee S-J, Park J-H, Lee $\mathrm{K}-\mathrm{P}$ et al., Enzymatic Synthesis and Properties of Highly Branched Rice Starch Amylose and Amylopectin Cluster,J Agric Food Chem, 2008, 56, 126-131.

3. Jyothi AN, Moorthy SN, RajasekharanKN, Effect of Crosslinking withEpichlorohydrin on the Properties of Cassava (ManihotesculentaCrantz) Starch.Starch/Stärke, 2006, 58, 292299.

4. Lawal OS, Lechner MD, Hartmann B, Kulicke W, Carboxymethyl Cocoyam Starch: Synthesis, Characterisation and Influence of Reaction Parameters, Starch/Stärke, 2007,59, 224233.

5. USP XXX/ NF XXV, Sodium Starch Glycolate. United States Pharmacopoeial Convention, Vol. II, Inc, Rockville, Maryland, 2007

6. BP, British Pharmacopoeia: the Stationery Office, London, Vol. I and II, 2009.

7. Jeremic KI, Stovanovic ZP, Stovanovic SM, Modification of Starch Properties, Hem Ind, 2000,54, 438-446.

8. Stojanovic Z, Jeremic K, Jovanovic S, Synthesis of Carboxymethyl StarchStarch/Stärke, 2000,52, 413-419.

9. Gebre-Mariam T, Schmidt PC, Isolation and Physico-chemical Propertiesof Enset Starch,Starch/Stärke, 1996, 48, 208-214.

10. Paulos G, Endale A, Bultosa G, Gebre-Mariam T, Isolation and Physicochemical Characterization of Cassava Starches Obtained from Different Regions of Ethiopia, Ethiop Pharm J, 2009,27, 42-54.

11. KittipongpatanaOS, Burapadaja S, Kittipongpatana N, $\begin{array}{llll}\text { CarboxymethylMungbean Starch as a New } & \end{array}$ PharmaceuticalGelling Agent for Topical Preparation,Drug DevInd Pharm, 2009, 35, 34-42.

12. Heinze T,Carboxymethyl Ethers of Cellulose and Starch - a Review,Химиярастительногосырья, 2005,3, 13-29.

13. Nwokocha LM, Ogumola GB, Carboxymethylation of Cassava Starch in Different Solvents and Solvent-Water Mixtures: Optimization of Reaction Conditions, J ApplSci, 2008, 8, 15811585.

14. Da G, Dufour D, Marouzé C, Thanh ML, Maréchal P-A, Cassava Starch Processing at Small Scale in North Vietnam, Starch/Stärke, 2008, 60, 358-372.

15. Jie Y, Wen-ren C, Manurung RM, Ganzeveld KJ, Heeres HJ, Exploratory Studies on the Carboxymethylation of Cassava Starch in Water-miscible Organic Media,Starch/Stärke, 2004,56,100-107.

16. Khalil MI, HashemA, Hebeish A, Carboxymethylation of Maize Starch, Starch/Stärke, 1990,42, 60-63.

17. Das MK, Ahmed AB, Formulation and Ex Vivo Evaluation of Rofecoxib Gel for Topical Application, Acta. Poloniae, PharmDrug Res, 2007,63, 461-467.

18. Das K, Dang R, Machale MU, Formulation and Evaluation of a Novel Herbal Gel of Stevia Extract, Iranian JDerm,2009, 12, 117-122.

19. Chen M, Liu X, Fahr A, Skin Penetration and Deposition of Carboxyfluorescein and Temoporfin from Different Lipid Vesicular Systems: In Vitro study with Finite and Infinite Dosage Application, Inter J Pharm,2011, 408, 223-234.

20. Sanna V, Peana AT, Moretti MDL, Effect of Vehicle on Diclofenac Sodium Permeation from New Topical Formulations: In Vitro and In Vivo Studies, Current Drug Deliv, 2009,6, 93-100.
21. Cs'oka I, Cs'anyi E, Zapantis G, Nagy E, Feh'er-Kiss A Horv'ath G, Blazs'o G, Er"osI, In Vitro and In Vivo Percutaneous Absorption of Topical Dosage Forms: Case Studies,Int J Pharm, 2005,291, 11-19.

22. Dhawan S, Medhi B, Chopra S, Formulation and Evaluation of DiltiazemHydrochloride Gels for the Treatment of Anal Fissures. Sciencia. Pharmaceutica, 2009,77, 465-482.

23. Peroni FHG, Rocha TS, Franco CML, Some Structural and Physicochemical Characteristics of Tuber and Root Starches,Food Sci Tech Int,2006, 12, 505-513.

24. Kesavanarayanan KS, Nappinnai M, Ilavarasan R, Topical Dosage Form of Valdecoxib: Preparation and Pharmacological Evaluation, Acta Pharm 2007,57, 199-209.

25. Bachhav YG, Patravale VB, Formulation of Meloxicam Gel for Topical Application: In Vitro and In Vivo Evaluation,Acta Pharm, 2010,60, 153-163.

26. Buhse L, Kolinski R, Westenberger B, Wokovich A, Spencer J, Chen CW, et al, Topical Drug Classification, Int J Pharm,2005, 295, 101-112.

27. Rupal J, Kaushal J, Mallikarjuna SC, Dipti P, Preparation and Evaluation of Topical Gel of Valdecoxib, Int J Pharm Sci Drug Res, 2010,2, 51-54.

28. Setty CM, Babubhai SR, Pathan IB, Development of Valdecoxib Topical Gels: Effect of Formulation Variables on the Release of Valdecoxib,Int J Pharmac PharmSci,2010, 2, 70-73.

29. Chow KT, Chan LW, Heng PWS, Characterization of Spreadability of Non-aqueous Ethylcellulose Gel Matrices Using Dynamic Contact Angle, J Pharm Sci,2008, 97, 3467-3482.

30. Chaudhary H, Kohli K, Amin S, Rathee P, Kumar V, Optimization and Formulation Design of Gels of Diclofenac and Curcumin for Transdermal Drug Delivery by Box-Behnken Statistical Design,J PharmSci, 2010,100, 580-593.

31. Patel RP, Patel HH, Baria AH, Formulation and Evaluation of CarbopolGel Containing Liposomes of Ketoconazole (Part-II), Int J Drug Deliv Tech,2009, 1, 42-45.

32. Tas C, Ozkan Y, Okyar A, Savaser A, In Vitro and Ex Vivo Permeation Studies of Etodolac from Hydrophilic Gels and Effect of Terpenes as Enhancers,Drug Deliv,2007, 14, 453-459.

33. Prakash PR, Rao NGR, Soujanya C, Formulation, Evaluation and Anti-inflammatory Activity of Topical Etoricoxib Gel,Asian J Pharm Clin Res,2010, 3, 126-129.

34. Ricci EJ, Lunardi LO, Nanclares DMA, Marchetti JM, Sustained Release of Lidocaine from Poloxamer 407 gels, Int J Pharm,2005, 288, 235-244.

35. Choi JS, Shin SC, Preparation and Evaluation of Pronoprofen Gel for Percutaneous Administration,Drug DevInd Pharm,2007, 33, 19-26.

36. Welin-Berger K, Neelissen JAM,Bergenstahl B, The Effect of Rheological Behaviour of a Topical Anaesthetic Formulation on the Release Permeation Rates of the Active Compound,Eur J Pharm Sci, 2001, 13, 309-318.

37. El Gendy AM, Jun HW, Kassem AA, In Vitro Release Studies of FlurbiprofenfromDifferent Topical Formulations, Drug DevInd Pharm, 2002,28, 823-831.

38. Wang YY, Hong CT, Chiu WT, Fang JY, In Vitro and In Vivo Evaluations of Topically Applied Capsaicin and Nonivamide from Hydrogels, Int J Pharm, 2001, 224, 89-104.

39. Hasçiçek C, Bediz-Ölçer A, Gönül N, Preparation and Evaluation of Different Gel Formulations for Transdermal Delivery of Meloxicam,Turk J PharmSci,2009, 6, 177-186. 